\title{
THE EFFECTS OF 6-MERCAPTOPURINE ON HOMOGRAFT REACTIONS *
}

\author{
By ROBERT SCHWARTZ † AND WILLIAM DAMESHEK WITH THE TECHNICAL \\ ASSISTANCE OF JANICE DONOVAN \\ (From the Blood Research Laboratory, a unit of the Ziskind Laboratories, New England Center \\ Hospital, and the Department of Medicine, Tufts University School of Medicine, \\ Boston, Mass.)
}

(Submitted December 28, 1959; accepted February 5, 1960)

Grafts of tissues or organs exchanged between genetically different individuals are ultimately destroyed by the recipient. It is generally conceded that the destruction of such foreign tissue (homograft reaction) is brought about by antibodies produced by the recipient in response to antigens present in the graft (1). If the formation of these antibodies could be prevented, the graft might then survive for a lengthy period of time. Such an effect has been obtained following exposure of experimental animals or of man to high doses of total body X-irradiation $(2,3)$. Recently, an antimetabolite, 6-mercaptopurine (6-MP), was found to have definite effects on the production of antibody. This analog of adenine sharply curtailed the formation of antibody in rabbits injected repeatedly with bovine serum albumin (4). It was later found that the primary immune response could be blocked completely by relatively small doses of 6-MP, while only weak effects on the secondary response were found with similar dosages (5). Six-MP also had the property of inducing a state closely resembling immunological tolerance to a single, purified protein antigen in adult rabbits (6). The drug appeared to exert its anti-immune action by a direct chemical effect on antibody-forming tissue (7). The possibility thus arose that 6-MP might delay or prevent the rejection of grafted tissue. The purpose of this paper is to describe the effect of this drug on the reactions of rabbits to homografts.

* Presented in part at the VIIth European Congress of Haematology, London, Sept. 7, 1959. Aided by grants from the United States Atomic Energy Commission, Contract AT(30-1)2032, and the National Cancer Institute, Contract CY-4168.

$\dagger$ Under tenure of a U. S. Public Health Service Fellowship, HF-7166(C).

\section{MATERIALS AND METHODS}

Fifty-three adult, outbred, randomly selected rabbits were used. Twenty-four of the animals had black fur and 29 had white. Sixteen control and 37 drug-treated animals were studied. All animals were housed in an air-conditioned room. Water and rabbit Purina chow were fed $a d$ lib.

The rabbits were anesthetized with intravenous Nembutal, $20 \mathrm{mg}$ per kg. Full thickness skin grafts, measuring approximately $2.5 \times 2.5 \mathrm{~cm}$, were fashioned from the dorsal surface of their ears. The grafts were sutured into place with fine silk thread; no dressings were applied. Each graft was inspected and palpated daily and any sign of edema, cyanosis or necrosis was recorded. A retrospective determination of the graft rejection time was made from the daily notes. This time was taken to be the first day on which clear-cut edema, cyanosis or necrosis appeared. Two types of graft exchanges were made with these squares of skin: autografts, in which the same animal was both donor and recipient, and homografts, in which the donor and recipient were different animals. Wherever possible the homografts were exchanged between black and white rabbits.

The control animals received no treatment. There were 4 groups of animals treated with 6-MP: A) 9 animals were treated with $6 \mathrm{mg}$ per $\mathrm{kg}$ per day for 2 weeks; B) 7 animals were treated with $10 \mathrm{mg}$ per $\mathrm{kg}$ per day for 2 weeks, then every other day until graft rejection occurred; C) 17 animals received $12 \mathrm{mg}$ per $\mathrm{kg}$ per day for 2 weeks then every other day until the homograft was rejected. Groups A, B and C received the drug by subcutaneous injection as previously described (5). A fourth group of 4 rabbits (D) received $6-\mathrm{MP}, 12 \mathrm{mg}$ per $\mathrm{kg}$ per day by mouth for 2 weeks, then every other day until the graft was rejected. For this purpose, the 6-MP was dissolved in a minimum volume of dilute alkali; further dilution of the drug was made in cherry syrup. A small gastric tube was fashioned from a soft rubber no. 14 urethral catheter. This catheter was inserted into the upper esophagus of the rabbit and the desired dose of 6-MP was injected into its open end by means of a $5 \mathrm{ml}$ syringe.

One or two weeks after rejection of the first homograft occurred, a second set of grafts was exchanged between pairs of rabbits. The donor and recipient of 
TABLE I

Effect of 6-mercaptopurine on first set skin homografts in rabbits

\begin{tabular}{|c|c|c|c|c|c|c|}
\hline Group & Dose & $\begin{array}{l}\text { Route of 6-MP } \\
\text { administration }\end{array}$ & Animals & MRT* & SD & $\mathbf{p}$ \\
\hline \multicolumn{3}{|c|}{$m g / k g / d a y$} & no. & days & & \\
\hline \multicolumn{3}{|c|}{ Controls } & 16 & 6.8 & 0.8 . & \\
\hline A & 6 & Subcutaneous & 9 & 10.0 & 0.3 & 0.1 \\
\hline B & 10 & Subcutaneous & 7 & 13.9 & 6.0 & 0.05 \\
\hline $\mathrm{C}$ & 12 & Subcutaneous & 17 & 17.8 & 7.4 & 0.01 \\
\hline D & 12 & Oral & 4 & 14.0 & 3.2 & 0.05 \\
\hline
\end{tabular}

* Mean rejection time.

the second graft were always the same as those of the first graft. Rejection time of the second grafts was determined as described above.

While no systematic attempt was made to study each graft histologically, selected sections of healed autografts, rejected homografts and retained homografts were stained with hematoxylin and eosin and studied microscopically.

\section{RESULTS}

\section{Reactions to initial grafts (first set reactions)}

The results are shown in Table I and Figures 1 through 4 . Of 59 autografts applied, 58 healed soundly with the ultimate regrowth of hair. One autograft sloughed within four days of its application due to hemorrhage in the graft bed. In the control homograft, the initial change was the development of edema or of cyanosis; this event

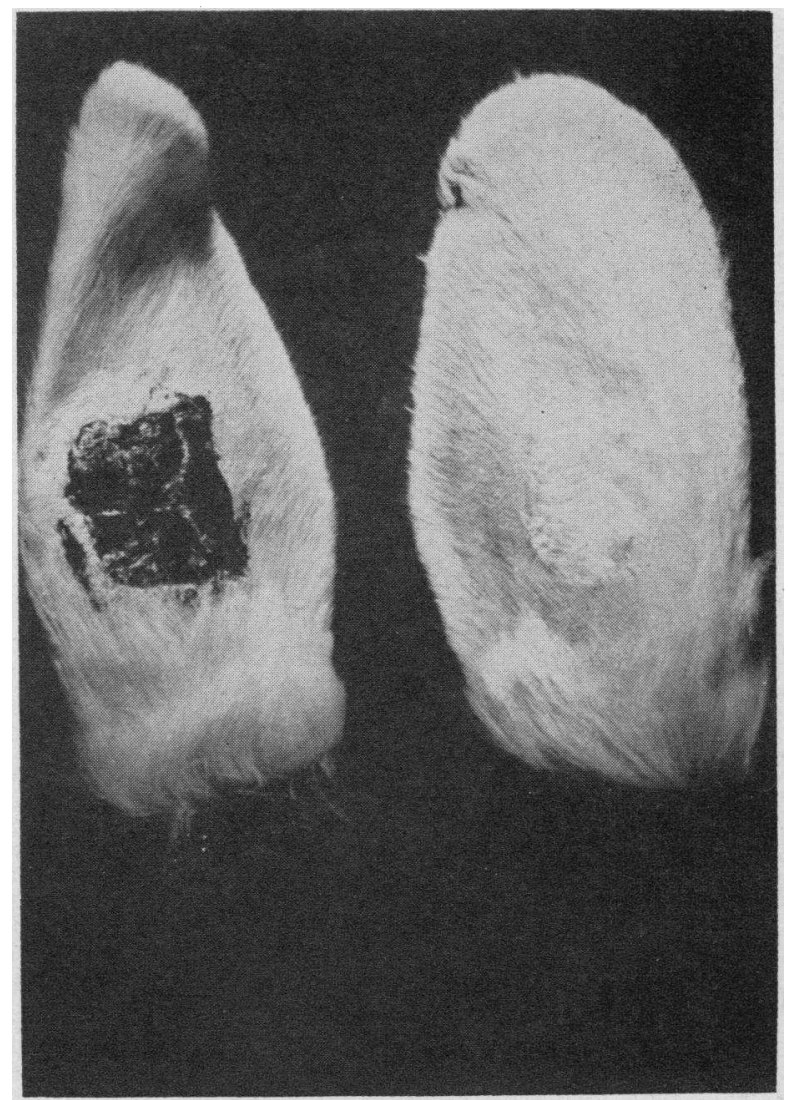

Fig. 1. Twelve day old Autograft (RIght) AND HOMOGRAFT (LEFT). The latter has been completely destroyed.

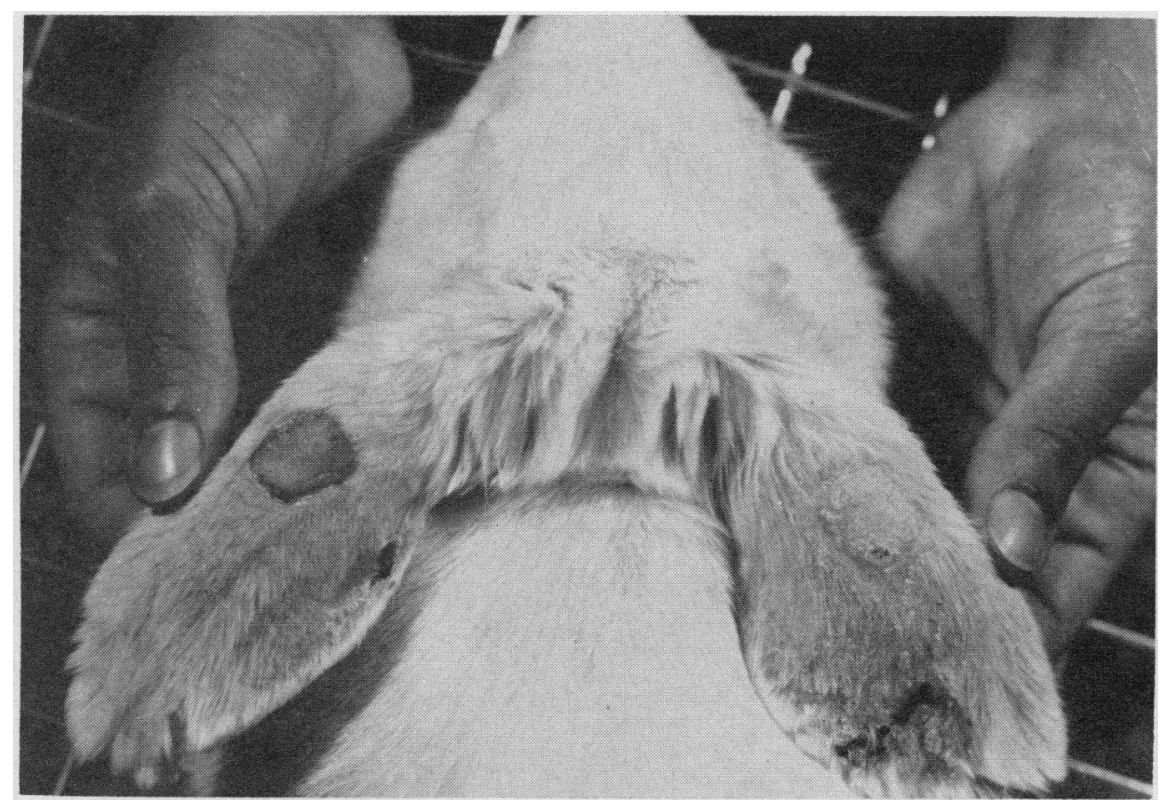

Fig. 2. ThiRTY-Four day old autograft (Right) AND homograft (LEFT) in a 6-MP-TREATED RABBIT. Tiny black hairs can be seen on the homograft. 


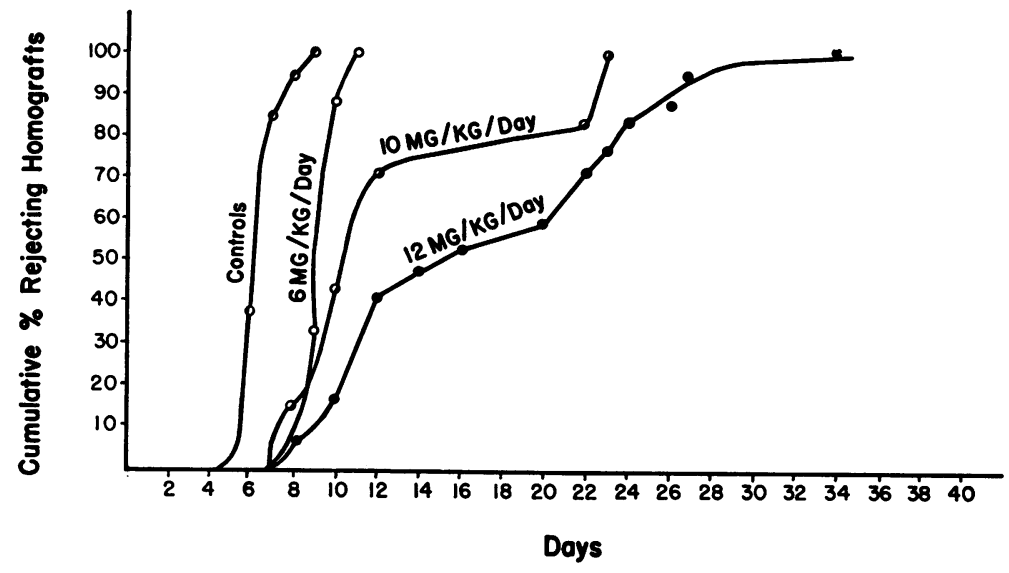

Fig. 3. EFFECT OF 6-MP ON REJECTION OF SKIN HOMOGRAFTS.

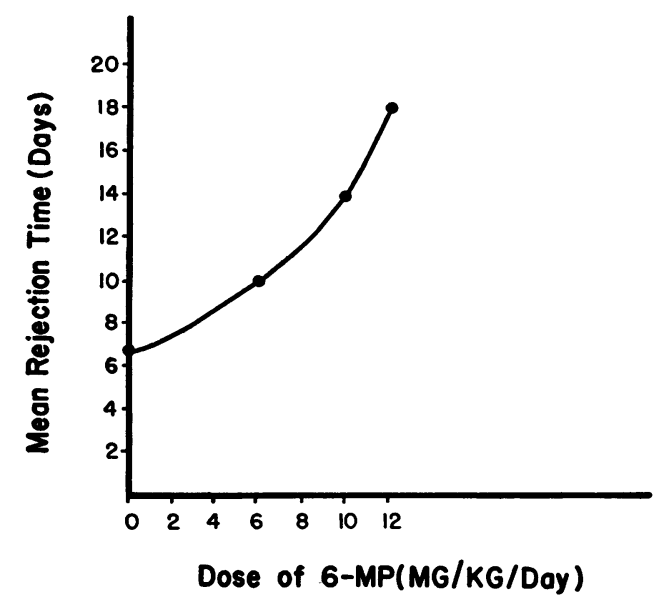

Fig. 4. EFFect of VARYING DOSES OF 6-MP ON THE MEAN REJECTION TIME OF SKIN HOMOGRAFTS.

was followed quickly by the appearance of obvious necrosis. Rejection of the homografts in the control animals occurred in a sudden, well defined manner that took place in most cases over a 24 hour period. In contrast to this mode of rejection, animals of Groups B, C and D frequently rejected their grafts in a much slower fashion, the entire

TABLE II

Behavior of second set skin homografts in rabbits

\begin{tabular}{|c|c|c|c|c|c|}
\hline \multicolumn{2}{|c|}{$\begin{array}{l}\text { Treatment with } \\
\text { first set grafts }\end{array}$} & \multirow[t]{2}{*}{$\begin{array}{l}\text { Route of } 6-\mathrm{MP} \\
\text { administration }\end{array}$} & \multirow{2}{*}{$\frac{\text { Animals }}{\text { no. }}$} & \multirow{2}{*}{$\frac{\text { MRT* }}{\text { days }}$} & \multirow[t]{2}{*}{ SD } \\
\hline & $m g / k g / d a y$ & & & & \\
\hline Controls & & & 11 & 4.4 & 1.8 \\
\hline Group A & 6 & Subcutaneous & 6 & 4.3 & 0.3 \\
\hline Group B & 10 & Subcutaneous & 4 & 2.7 & 1.0 \\
\hline Group C & 12 & Subcutaneous & 6 & 4.4 & 0.9 \\
\hline
\end{tabular}

* Mean rejection time. reaction taking several days to develop. The first sign of graft rejection in these animals treated with 6-MP was frequently the appearance of a light, fluffy scale on the epidermal surface of the graft. At times it was difficult to determine the

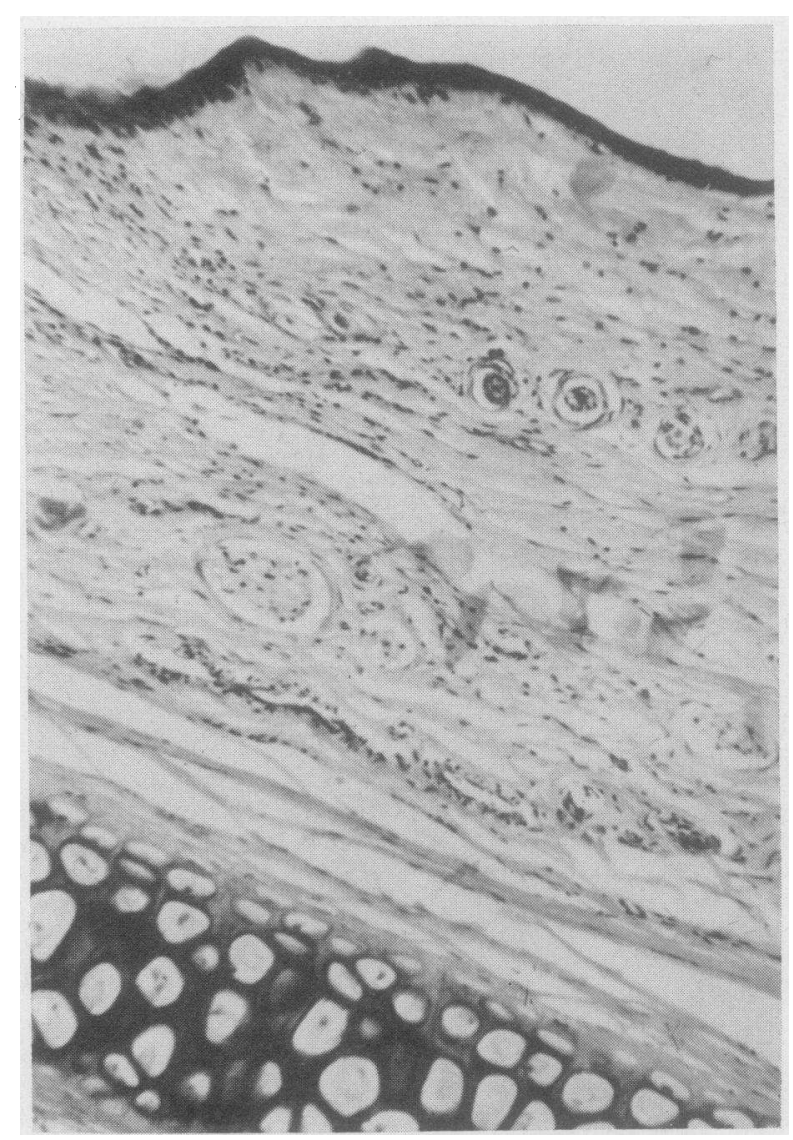

Fig. 5. Histological section of healing autograft. Note sebaceous glands. 


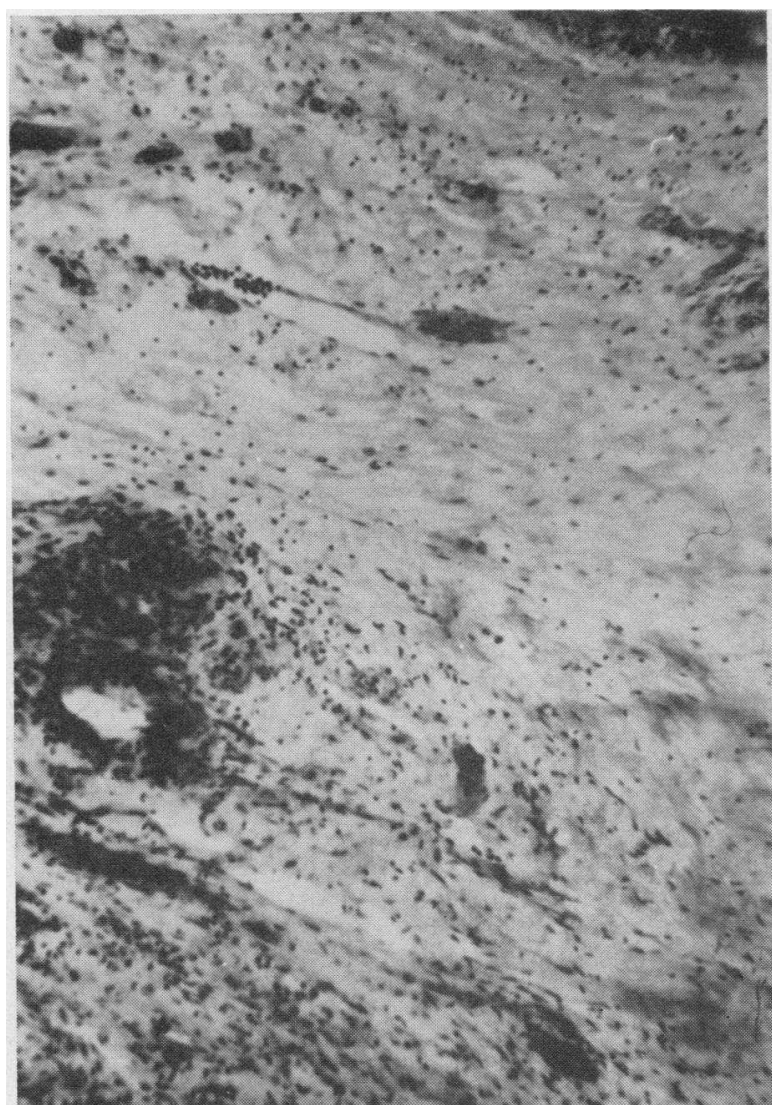

Fig. 6. Rejecting homograft. Note perivascular inflammation and edema.

precise endpoint of graft rejection in these three groups of rabbits, although within a few days after the appearance of epidermal scaling obvious signs of rejection usually appeared.

Growth of hair appeared on the homografts of four animals of Group C (treated with $12 \mathrm{mg}$ per $\mathrm{kg}$ per day of 6-MP). These grafts had survived for $24,28,30$ and 34 days. In each case the color of the hair was that of the donor animal (Figure 2). Within a week after the appearance of hair, clear-cut signs of rejection appeared in these grafts. Growth of hair occurred in none of the untreated animals.

As can be seen from Figure 4, successively higher doses of 6-MP produced a progressive rise in the mean rejection time of the homograft. A few animals were given 6-MP in a dose of $15 \mathrm{mg}$ per $\mathrm{kg}$ per day in an attempt to prolong further the retention of homografts. This dose, however, proved too toxic and additional studies at this dosage were not done. Four animals were given 12 mg per kg per day by mouth. No advantage of oral over subcutaneous administration was observed, and the homografts in these four animals were rejected after $10,12,14$ and 15 days.

\section{Reactions to second grafts (second set reactions, Table II)}

The rejection of the second graft from the original donor was characterized by accelerated pace and increased vigor; this is the type of behavior expected in a sensitized animal. No differences in the rejection times or mode of rejection of the second set of skin grafts were found among the various groups.

\section{Histological observations}

Autografts. The appearance of the autografts was that of well healed wounds; that is, at the junction of the graft and its bed, well vascularized "young" fibrous tissue was present. Inflamma-

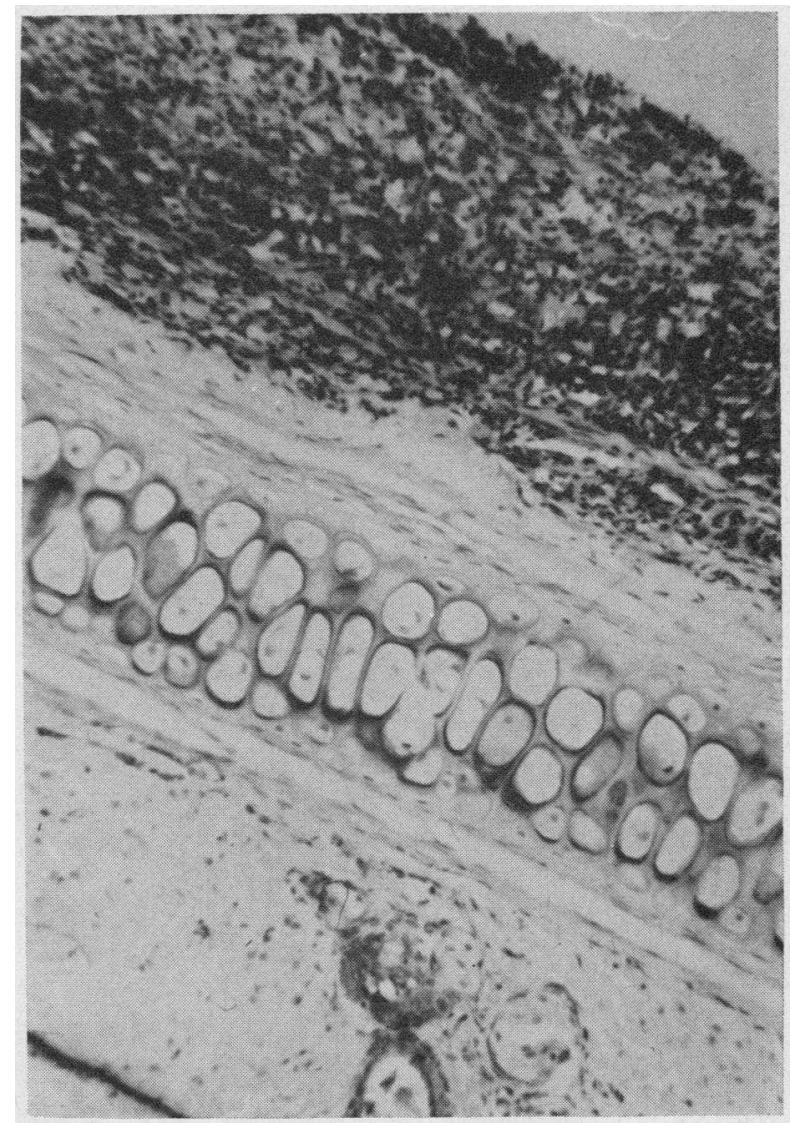

Fig. 7. SECOND SET RESPONSE SHOWING EXTENSIVE NECROSIS OF THE HOMOGRAFT, 


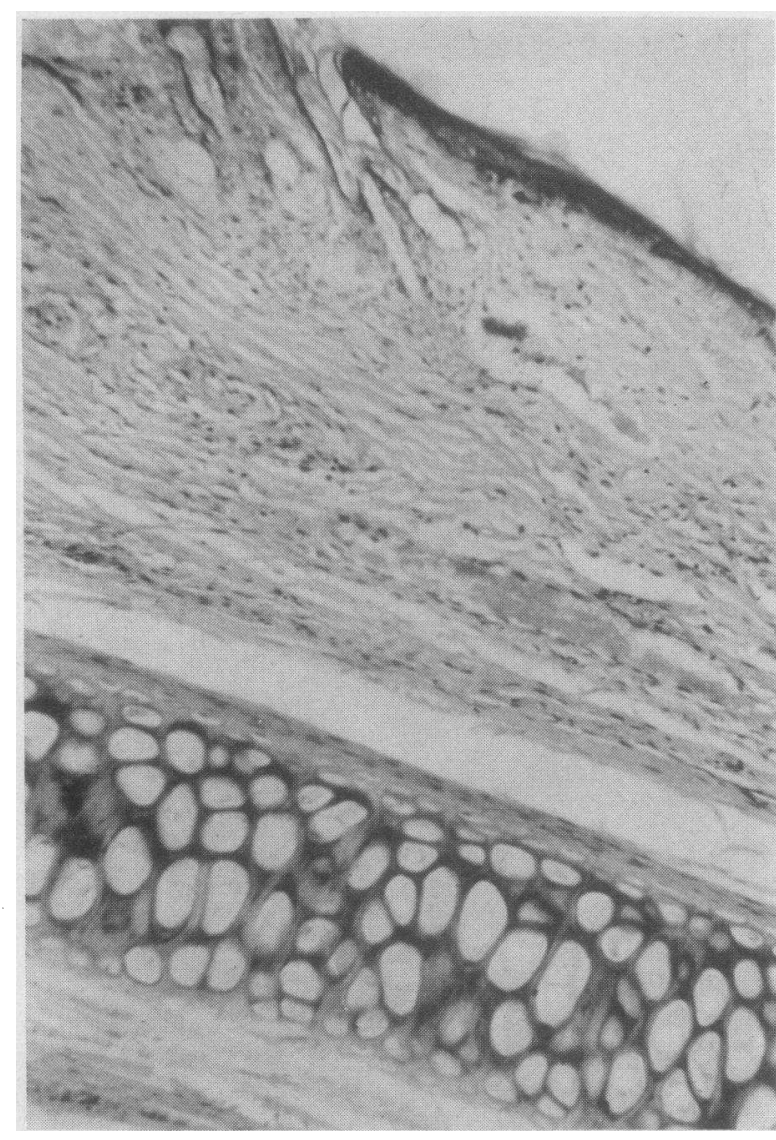

Fig. 8. Retained homograft from 6-MP-treated ANIMAL. Note hair shaft and lack of inflammation.

tory cells were absent. Skin appendages were normal in appearance (Figure 5).

Control homografts. The early stages of rejection were characterized by perivascular inflammatory exudates, focal degeneration of collagen and slight scattering of inflammatory cells throughout the graft. Later, the inflammatory exudate was marked, with large areas of necrosis and hemorrhage (Figures 6 and 7 ).

Retained, grossly normal homografts. Prior to rejection no essential differences were noted between autografts and specimens from this group (Figure 8).

\section{DISCUSSION}

While no permanent homograft "takes" were observed in this study, a statistically significant prolongation of the mean rejection time occurred in the animals treated with 6-MP in doses of 10 and $12 \mathrm{mg}$ per $\mathrm{kg}$ per day. The mean rejection time in the group treated with $12 \mathrm{mg}$ per $\mathrm{kg}$ per day (17.8 days) was comparable with the results obtained in rabbits treated with lethal total body irradiation $(1,100 \mathrm{r})$ but without marrow-transplantation (8). With this type of treatment, a mean rejection time of 21 days was obtained. It is of interest to note that a dose of $400 \mathrm{r}$ in rabbits is sufficient to block effectively antibody formation to a purified protein antigen (9), while the same dose is only partially effective in preventing the homograft reaction. A similar result is observed following treatment with 6-MP. This finding may be due to several factors: 1) differences among the immune responses to intravenously injected purified antigens and locally applied tissue grafts; 2) differences in the "antigenicity" of purified antigens and tissue grafts; 3 ) immunization of animals with living tissue, in which there is continuous proliferation of antigenic cells, is obviously different from the immunization of an animal with a single injection of a "dead" antigen. A grafted animal may thus be considered as one in which a continuous "infusion" of antigen occurs. Whether or not 6-MP is effective in blocking formation of antibody when purified antigen is infused continuously is now under study.

In these experiments an attempt was made to determine whether or not any degree of tissue tolerance could be induced by 6-MP. In a previous study it was shown that "tolerance" to a purified protein antigen could be established in adult rabbits by treatment with this drug (6). The observations in the present study demonstrate that a state of immunological tolerance to skin grafts could not be established with the dosage of 6-MP used, since the rejection time of the second set grafts was similar in all cases. A state of tolerance would have been indicated by prolonged retention of the second set graft in the animals previously treated with 6-MP.

It is clear from the microscopic study of sections that 6-MP did not impair wound healing, since sections taken from grafts in the animals treated with this drug showed that the fibroblastic and vascular proliferation was identical with that seen in the controls. In the sections of homografts which survived for long periods of time, there was no evidence of a "partial" rejection or of a suppressed inflammatory reaction. The appearance of these grafts was identical with that of the autografts, indicating that under the con- 
ditions of these experiments, homograft rejection was an "all or none" phenomenon. Once begun, transplantation immune mechanisms may thus be extremely difficult to overcome. It is not understood why breakdown of the homograft occurred after an apparently satisfactory "take." There is good evidence that failure of treatment with 6-MP occurs in acute leukemia after the appearance of cells resistant to the biochemical effects of this agent (10). Whether or not this phenomenon can occur in antibody-forming cells is problematical but not unlikely. Treatment of the homograft reaction with combinations of antimetabolites, either in tandem or in sequence, may, as in the treatment of acute leukemia, yield further prolongation of graft retention.

A growing body of evidence now indicates that substances classifiable as antimetabolites, of which 6-MP may be considered a prototype, are active "anti-immune" agents (11-15). This activity of these agents may have importance in respect to a widely used tool in the screening of chemotherapeutic agents for the treatment of cancer, namely, the transplantable tumor (16). As can be seen from the data presented here, a useful chemotherapeutic agent actually enhances the growth of a skin transplant. It is conceivable that the recognition of other clinically useful antitiumor chemicals may be missed by such a screening program if they enhance the growth of transplanted tumors by diminishing the host's normal immune response to tissue transplants. It has been found that certain antimetabolites are more potent, on a weight basis, in blocking antibody formation than in carcinolytic activity (17). Such a differential effect might further hinder the screening of antitumor agents in the transplantable tumor system. Some recent studies have indicated that the growth of certain transplanted tumors of mice is actually enhanced by antimetabolite treatment $(18,19)$.

The antimetabolite 6-MP is clearly not a solution to the problem of the homograft reaction. Its toxicity in man and its limited effects in the rabbit preclude its immediate application to problems of tissue transplantation in humans. It may, however, offer a clue to the direction that further studies should take, especially since the effects of this chemical agent are closely comparable with those obtained with total body irradiation, a far more formidable procedure.

\section{SUMMARY}

The effects on the homograft reaction of 6-mercaptopurine, an inhibtor of nucleic acid metabolism, were studied. It was found that the subcutaneous administration of this drug in a dose of $12 \mathrm{mg}$ per $\mathrm{kg}$ per day could triple the survival time of skin homografts in rabbits.

\section{ACKNOWLEDGMENTS}

Mr. Richard Rubinson gave valuable assistance during his tenure as a student research assistant, June through September, 1959. The authors are indebted to Dr. Richard Wilson for his instruction in the technique of skin grafting in rabbits. Dr. W. J. Mitus gave valuable assistance with the interpretation of histology of the various grafts.

\section{REFERENCES}

1. Medawar, P. B. The immunology of transplantation. Harvey Lect. 1956-57, pp. 144-176.

2. Lindley, D. L., Odell, T. T., Jr., and Tausche, F. G. Implantation of functional erythropoietic elements following total-body irradiation. Proc. Soc. exp. Biol. (N. Y.) 1955, 90, 512.

3. Mathé, Georges. Application of hematopoietic cell grafts to the treatment of leukemia and allied diseases. Blood. In press.

4. Schwartz, R., Stack, J., and Dameshek, W. Effect of 6-mercaptopurine on antibody production. Proc. Soc. exp. Biol. (N. Y.) 1958, 99, 164.

5. Schwartz, R., Eisner, A., and Dameshek, W. The effect of 6-mercaptopurine on primary and secondary immune responses. J. clin. Invest. 1959, 38, 1394.

6. Schwartz, R., and Dameshek, W. Drug-induced immunological tolerance. Nature (Lond.) 1959, 183, 1682.

7. Schwartz, R., and Eisner, A. Effect of 6-mercaptopurine on immune responses. Clin. Res. 1959, 7, 39.

8. Wilson, R. E., Dealy, J. B., Jr., Sadowsky, N. L., Corson, J. M., and Murray, J. E. Transplantation of homologous bone marow and skin from common multiple donors following total body irradiation. Surgery 1959, 46, 261.

9. Taliaferro, W. H., and Taliaferro, L. G. Effect of $\mathrm{x}$-rays on immunity: A review. J. Immunol. 1951, 66, 181.

10. Law, L. W. The phenomena of resistance and dependence in leukemic cells. Ciba Found. Symp. on Leukemia Research. London, J. \& A. Churchill, 1954, pp. 105-126.

11. Malmgren, R. A., Bennison, B. E., and McKinley, T. W., Jr. Reduced antibody titers in mice treated with carcinogenic and cancer chemotherapeutic agents. Proc. Soc. exp. Biol. (N. Y.) 1952, 79, 484. 
12. Malmgren, R. A., Bennison, B. E., and McKinley, T. W. The effect of guanazolo on antibody formation. J. nat. Cancer Inst. 1952, 12, 807.

13. Dutton, R. W., Dutton, A. H., and George, M. Effect of 8-azaguanine on antibody synthesis in vitro. Nature (Lond.) 1958, 182, 1377.

14. Wissler, R. W., Frazier, L. F., Soules, K. H., Barker, P., and Bristow, E. C., III. The acute effects of beta $_{3}$ thienylalanine in the adult male albino rat; observations on nitrogen balance, antibody formation, and tumor growth. Arch. Path. (Chicago) $1956,62,62$.
15. Berenbaum, M. C. Effect of cytotoxic agents on antibody production. Nature (Lond.) 1960, 185, 167.

16. Gelhorn, A., and Hirschberg, E., Eds. Investigation of diverse systems for cancer chemotherapy screening. Cancer Res. 1955, suppl. 3, pp. 1-125.

17. Schwartz, R. Unpublished observations.

18. Potter, M., and Haas, V. H. Relationships between lymphocytic choriomeningitis virus, amethopterin, and an amethopterin-resistant lymphocytic neoplasm in mice. J. nat. Cancer Inst. 1959, 22, 801.

19. Martinez, M. Personal communication. 